\title{
A BIOCHEMICAL MULTI-SPECIES QUALITY MODEL OF A DRINKING WATER DISTRIBUTION SYSTEM FOR SIMULATION AND DESIGN
}

\author{
KrZysztof ARMINSKI*, Tomasz ZUBOWICZ* MieteK A. BRDYS *,** \\ * Department of Control Systems Engineering \\ Gdańsk University of Technology, ul. G. Narutowicza 11/12, 80-233 Gdańsk, Poland \\ e-mail: \{krzysztof.arminski, tomasz.zubowicz\} @gmail.com m.brdys@ely.pg.gda.pl] \\ ** Department of Electronic, Electrical and Computer Engineering, College of Engineering and Physical Sciences \\ University of Birmingham, Edgbaston, Birmingham B15 2TT, UK \\ e-mail: m.brdys@bham.ac.uk
}

\begin{abstract}
Drinking Water Distribution Systems (DWDSs) play a key role in sustainable development of modern society. They are classified as critical infrastructure systems. This imposes a large set of highly demanding requirements on the DWDS operation and requires dedicated algorithms for on-line monitoring and control to tackle related problems. Requirements on DWDS availability restrict the usability of the real plant in the design phase. Thus, a proper model is crucial. Within this paper a DWDS multi-species quality model for simulation and design is derived. The model is composed of multiple highly inter-connected modules which are introduced to represent chemical and biological species and (above all) their interactions. The chemical part includes the processes of chloramine decay with additional bromine catalysis and reaction with nitrogen compounds. The biological part consists of both heterotrophic and chemo-autotrophic bacteria species. The heterotrophic bacteria are assumed to consume assimilable organic carbon. Autotrophs are ammonia oxidizing bacteria and nitrite oxidizing bacteria species which are responsible for nitrification processes. Moreover, Disinfection By-Products (DBPs) are also considered. Two numerical examples illustrate the derived model's behaviour in normal and disturbance operational states.
\end{abstract}

Keywords: multi-species, chloramine, quality, drinking water distribution system, critical infrastructure system.

\section{Introduction}

Water is a critical factor conditioning the existence of life on Earth. It also became a fundamental resource without which the modern society could not develop or even maintain its current lifestyle. Guaranteeing a common access to safe water is one of the most important tasks in each society. This point of view is strongly supported within the European Union and is guided by the European law (EU Council Directive, 1998).

Providing access to safe water is not a trivial task. Drinking Water Distribution Systems (DWDSs) belong to the group of so-called Critical Infrastructure Systems (CISs), which are recognised as a source of fundamental resources, guaranteeing a sustainable development of the society. It is obvious that to achieve the above-mentioned goal, appropriate monitoring, control and security structures as well as algorithms are required. A DWDS-CIS in general is a large scale complex system usually spatially distributed over a large area. The development of mechanisms able to handle such a dynamical system is not something that can be easily done at the plant site, which is why having a proper model is essential.

In the literature several groups of models regarding DWDS quality may be found. The first type is empirically derived black box models with parameters laboriously fit to measurement data in order to obtain a good measurement explanation and prediction capabilities. These models are utilised both to explain the process variables or technological outputs. In the work of Sadiq and Rodriguez (2004) a comprehensive set of this type of models was gathered. The second group consists of dynamic models of first (e.g., Rossman et al., 1994) or second order (e.g., Clark et al., 2002; Kohpaei and Sathasivan, 2011). Both groups are broadly utilised to model the disinfectant decay. The third 
group consists of more sophisticated nonlinear dynamic models. These are usually utilised to model biological processes (e.g., the Monod kinetic model—a simplified structure often used to model biological regrowth). Also the Disinfection By-Products (DBPs) formation model belongs to this group. DWDS quality processes most commonly addressed in literature are the decomposition of disinfectant (e.g., Rossman et al., 1994; Clark et al., 2002; Helbling and VanBriesen, 2009), biological regrowth (e.g., Jegatheesan et al., 2003; Digiano and Zhang, 2008; Liu et al., 2005b; Shang et al., 2008), corrosion (Frateur et al., 1999). However, most of the works that may be found address a single group of a chemical compound or a biological species with measurable interaction from other groups.

Joint chemical and biological models of DWDS quality processes are still rather modestly addressed in the literature. An example of this type of model is an aggregated multi-species transportation model of microorganisms, disinfectant and substrates in water pipes based on mass balance equations presented by Lu et al. (1995). However, it lacked some of the key components perused in this work, e.g., the formation of DBPs.

Shang et al. (2008) studied a chloramine decay model (originally introduced by Vikesland et al. (2001)) in simulation utilising the EPANET-MSX environment. Extensive research on chlorine aqueous chemistry may be found in a review paper by Deborae and von Guten (2008). A chlorine decay model and the formation of haloacetic acids in drinking water were addressed by, e.g., Liu and Qi (2010).

A complex biological regrowth model (based on Monod kinetics) and its calibration were addressed by Jegatheesan et al. (2003). A sensitivity analysis of simple biological regrowth model was performed by Digiano and Zhang (2008) by applying sensitivity equations. Finding a numerical solution to a model of bacterial regrowth in the DWDS environment was studied by Zhang et al. (2004). Nitrification processes in chloraminated drinking water were investigated by Liu et al. (2005a; 2005b) based on a pilot DWDS. Aspects related to biofilm formation in drinking water were addressed in the context of Assimilable Organic Carbon (AOC) and Dissolved Organic Carbon (DOC) impact on the process kinetics in the work of van der Kooij et al. (1995). A full scale study on multiple DWDSs towards identifying factors related to coliform regrowth was presented by LeChevallier et al. (1996). A combined planktonic and biofilm growth model was obtained as a result of the TECHNEAU project (Hammes et al., 2007).

DBP formation was addressed by, e.g., Nokes et al. (1999), Muellner et al. (2007), Chowdhury et al. (2009) or Liu and Qi (2010). The cancerogenous effects of DBPs on human health were discussed by, e.g., Hrudey (2009), Bull et al. (2011) and the World Health Organisation (2005).
In this work a grey box biochemical model for simulation and design purposes is developed by aggregating multiple chemical and biological models into one highly interconnected structure. The goal of constructing this model is to derive a dynamic model structure which will inherit the characteristic of both chemical and biological dynamics and will introduce a strong interaction between these two groups (resembling natural interconnections). It is not the main goal of the research to obtain a model which could be easily calibrated and directly applied to solve problems related to monitoring or control of DWDS quality, but good care of model parameter validity and some means of obtaining them are necessary and as such this is addressed in this work. The main goal of the paper is to capture the class of dynamics that resembles the DWDS environment and by doing so will serve as a tool for deriving and verifying simplified model structures more suitable for solving tasks related to DWDS on-line monitoring, control (e.g., Łangowski and Brdys, 2007; Nowicki et al., 2012). The authors assume that, if the derived simplified structure can be tuned to handle tasks in the environment simulated by utilising the derived 'full scale' model, it is very likely to obtain similar results in practice. This most certainly will require strong robustness from the derived algorithms based on simplified structures as the model presented in this work is defiantly not 'perfect'. Moreover, exploiting such a rich dynamic structure can be used to capture (in a single simulation model) a transition between normal and disturbance operational states (see Brdys, 2010). This can prove to be crucial for the development of monitoring and control mechanisms able to handle the DWDS dynamics in a wide range of operational conditions.

The original contribution of this work is integration of chemical and biological models by introduction of appropriate interactions between them in order to obtain a biochemical multi-species quality model of the DWDS environment that maintains the internal stoichiometric relationships. Moreover, a module accounting for DBP formation is added as one of the key components. Furthermore, the so-called technological outputs (e.g., total chlorine, DBPs, biomass, DOC, alkalinity, $\mathrm{pH}$ ) are introduced as model measurement outputs. The resulting model has an open structure (Arminski and Zubowicz, 2011) which makes it relatively easy to add new mechanisms if necessary.

This paper is organised as follows. In Section 2 a general introduction to mechanisms utilised to model chemical and biological processes within network environments of DWDSs is presented. Section 3 addresses the proposed model structure. In Section 4 model formulation is given. Section 6 presents the simulation experiments, results and discussion. Finally, Section 7 concludes the paper. 


\section{Modelling DWDS quality processes}

2.1. Processes implied by the DWDS structure. The network structure of the DWDS implies that the processes to be regarded in the model not only change with time but also depend on the position in space. The mechanism that guides this phenomenon is represented by an advective-reactive scheme (e.g., Zhang et al., 2004) and in general is given by

$$
\partial_{t} C_{j}^{i}= \begin{cases}-v_{j} \partial_{x_{j}} C_{j}^{i}+\Xi_{p}^{i}, & \text { in bulk flow, } \\ \Xi_{p}^{i}, & \text { at pipe wall, }\end{cases}
$$

where $v_{j} \triangleq v_{j}(t)$ is the medium velocity, $x_{j}$ is the distance from the beginning of the $j$-th pipe, $x_{j} \in$ $\left[0 ; x_{j}^{\max }\right], x_{j}^{\max }$ is the length of the $j$-th pipe, $C_{j}^{i} \triangleq$ $C_{j}^{i}\left(t, x, v_{j}\right)$ is the $i$-th species concentration in the $j$-th pipe, $\Xi_{p}^{i} \triangleq \Xi_{p}^{i}\left(\mathbf{C}_{j}, v_{j}, s_{j}\right)$ are the quality processes dependent on all species concentrations, $s_{j}$ is the contact surface of the pipe wall, $t$ is time; $i$ iterates the state variables and $j$ the pipes of the network.

Note that the interaction between the bulk and wall species is integrated into $\Xi_{p}^{i}$.

Since DWDS consists also of tanks, the following model needs to be considered:

$$
d_{t}\left(C_{j}^{i} V_{l}\right)=F_{\text {in }} C_{\text {inl }}^{i}-F_{\text {out }} C_{l}^{i}+V_{l} \Xi_{l}^{i},
$$

where $F_{\text {in }}$ and $F_{\text {out }}$ are the inflow and outflows, respectively, $C_{\mathrm{inl}}^{i}$ is the concentration of the $i$-th species in the tank inflow, $V_{l} \triangleq V_{l}(t)$ is the volume of the medium contained in the $l$-th tank, $\Xi_{l}^{i} \triangleq \Xi_{l}^{i}\left(\mathbf{C}_{l}\right)$ are the quality processes dependent on all species concentrations and it is assumed that they may be different from $\Xi_{p}^{i}$. Here $l$ iterates the tank number.

The quality reaction processes for the pipes can be described in general as

$$
\boldsymbol{\Xi}_{p}=\boldsymbol{\Lambda} \times \mathbf{r}_{\mathbf{p}}
$$

where $\boldsymbol{\Xi}_{p}=\left[\Xi_{p}^{1}, \Xi_{p}^{2}, \ldots, \Xi_{p}^{n}\right]^{T}$ and $n$ is the total number of processes and state variables as well, $\boldsymbol{\Lambda}$ is the stoichiometric coefficient matrix, $\mathbf{r}_{\mathbf{p}} \triangleq \mathbf{r}_{\mathbf{p}}\left(\mathbf{C}_{l}, v_{l}, s_{l}\right)$ is the fundamental process rate vector and $\mathbf{r}_{\mathrm{p}}=$ $\left[r_{p}^{1}, r_{p}^{2}, \ldots, r_{p}^{z}\right]^{T}$ and $z$ denote the processes involved in the model. The tanks are treated analogously.

Also the following assumption is made: the transportation mechanisms are considered only in the axial direction of the pipe; mixing in the tanks and at the nodes of the network is considered to be ideal. As the quality model is highly dependent on the quantity, that is, the flows and pressures in the DWDS, complimentary equations are required to obtain a full-scale model. To keep this work compact, the authors omit this part, which may be found in, e.g., the work of Brdys and Ulanicki (1994).
2.2. Chemical reactions. Two types of mathematical models are utilized to represent chemical reactions, (Davis and Robert, 2003), namely, kinetic (dynamic) and equilibrium (static) models. Let us consider a dissociation reaction

$$
a_{s} \mathbf{A}_{s} \underset{k_{-1}}{\stackrel{k_{1}}{\rightleftharpoons}} b_{s} \mathbf{B}_{s}+c_{s} \mathbf{C}_{s},
$$

where $\mathbf{A}_{s}$ is the reactant, $\mathbf{B}_{s}, \mathbf{C}_{s}$ are the reaction products, $a_{s}, b_{s}, c_{s}$ are reaction coefficients, $k_{1}$ and $k_{-1}$ yield the reaction kinetic constants, which can differ depending on the direction of the reaction occurrence.

The kinetic model of (4) yields

$$
v=-a_{s}^{-1} d_{t}\left[\mathbf{A}_{s}\right]=b_{s}^{-1} d_{t}\left[\mathbf{B}_{s}\right]=c_{s}^{-1} d_{t}\left[\mathbf{C}_{s}\right],
$$

where [.] is the molar concentration of given chemical species. On the other hand,

$$
v=k_{1}\left[\mathbf{A}_{s}\right]^{a_{o}}-k_{-1}\left[\mathbf{B}_{s}\right]^{b_{o}}\left[\mathbf{C}_{s}\right]^{c_{o}},
$$

where $a_{o}, b_{o}, c_{o}$ represent the kinetics order. Note that if the process is decomposed to elementary reactions then $a_{o}, b_{o}, c_{o}$ representing the kinetics order will be considered equal to stoichiometric coefficients. Higher orders are utilised when an approximation of single or multiple reactions is made due to a fully identified structure and/or parameters. Utilising (5) and (6) results in the kinetic model of the substances involved in (4).

Taking $v=0$ yields the equilibrium model

$$
K=k_{1}\left(k_{-1}\right)^{-1}=\left[\mathbf{B}_{\mathbf{s}}\right]^{b_{o}}\left[\mathbf{C}_{\mathbf{s}}\right]^{c_{o}}\left[\mathbf{A}_{\mathbf{s}}\right]^{-a_{o}},
$$

where $\mathrm{K}$ denotes the ratio of reaction products to reaction substrate concentrations in a steady state. In chemical engineering, equilibrium models are parametrized by the equilibrium constant $p K$ defined as $p K=-\log _{10}(K)$. This notation is convenient when the influence of $p H$ on the reaction kinetics is be taken into consideration.

2.3. Biological species. The biological regrowth model considered in this work is based on the Monod type kinetics. It is assumed that the bacteria undergo in general the processes of growth, death, lysis and inhibition in the presence of disinfection substances. The core model structure utilised in this study was adopted from the work by Jegatheesan et al. (2003). It considers of following specific processes: attachment of live bacteria to pipe walls, attachment of dead bacteria to pipe walls, detachment of live biofilm bacteria from pipe walls, detachment of dead biofilm bacteria from pipe walls, free bacteria growth; biofilm growth, free bacteria mortality, biofilm mortality, lysis of dead free bacteria, lysis of dead biofilm, carbohydrates extracellular biosynthesis, protein extracellular biosynthesis, (AOC) bio-hydrolysis, which are formulated respectively by

$$
\left.\mathrm{d}_{t} X_{L}^{\gamma}\right|_{\text {attachment }}=k_{a}^{\gamma} X_{L}^{\gamma}\left(1-X_{L b}^{\gamma} X_{\text {sat }}^{\gamma}{ }^{-1}\right),
$$




$$
\begin{gathered}
\left.\mathrm{d}_{t} X_{D}^{\gamma}\right|_{\text {attachment }}=k_{a}^{\gamma} X_{D}^{\gamma}\left(1-X_{D b}^{\gamma} X_{\text {sat }}^{\gamma}{ }^{-1}\right), \\
\left.\mathrm{d}_{t} X_{L}^{\gamma}\right|_{\text {detachment }}=k_{d}^{\gamma} X_{L b}^{\gamma}, \\
\left.\mathrm{d}_{t} X_{D b}^{\gamma}\right|_{\text {detachment }}=k_{d}^{\gamma} X_{D b}^{\gamma}, \\
\left.\mathrm{d}_{t} X_{L}^{\gamma}\right|_{\text {growth }}=\mu_{\text {spec }} X_{L}^{\gamma}, \\
\left.\mathrm{d}_{t} X_{L b}^{\gamma}\right|_{\text {growth }}=\mu_{\text {spec-bio }}^{\gamma} X_{L b \gamma}, \\
\left.\mathrm{d}_{t} X_{L}^{\gamma}\right|_{\text {mortality }}=\mu_{\text {death }}^{\gamma} X_{L}^{\gamma}, \\
\left.\mathrm{d}_{t} X_{L b}^{\gamma}\right|_{\text {mortality }}=\mu_{\text {death-bio }}^{\gamma} X_{L b}^{\gamma}, \\
\left.\mathrm{d}_{t} X_{D}^{\gamma}\right|_{\text {lysis }}=\left(X_{D}^{\gamma}-X_{D 0}^{\gamma}\right), \\
\left.\mathrm{d}_{t} X_{D b}^{\gamma}\right|_{\text {lysis }}=\left(X_{D b}^{\gamma}-X_{D b 0}^{\gamma}\right), \\
\mathrm{d}_{t} X_{C}=k_{1 C} X_{L b} \frac{S_{A O C}}{k_{2 C}+k_{3 C} S_{C l}^{t o t}}-k_{d C} X_{C}, \\
\mathrm{~d}_{t} X_{P}=k_{1 P} X_{L b} \frac{S_{A O C}}{k_{2 P}+k_{3 P} S_{C l}^{t o t}}-k_{d P} X_{P}, \\
\left.\mathrm{~d}_{t} C_{A O C}\right|_{\text {hydrolysis }}=k_{h} X_{L},
\end{gathered}
$$

where $X_{L}^{\gamma}, X_{D}^{\gamma}, X_{L b}^{\gamma}, X_{D b}^{\gamma}, X_{C}^{\gamma}, X_{P}^{\gamma}$ are the bacterial regrowth model state variables given for the $\gamma$-th bacterial species $k_{a}^{\gamma}$ and $k_{d}^{\gamma}$ are the attachment and detachment coefficients, respectively, $X_{s a t}^{\gamma}$ is the bacteria saturation concentration, $\mu_{\text {spec }}^{\gamma}$ and $\mu_{\text {spec-bio }}^{\gamma}$ are the specific growth rates of the free bacteria and biofilm, respectively, $\mu_{\text {death }}^{\gamma}$ and $\mu_{\text {death-bio }}^{\gamma}$ are the mortality rates of the free bacteria and the biofilm, respectively, $k_{l}^{\gamma}$ is the lysis rate constant, $X_{D 0}^{\gamma}$ and $X_{D b 0}^{\gamma}$ denote dead cells in bulk flow and biofilm, respectively, $k_{1 C}, k_{2 C}, k_{3 C}, k_{d C}$ and $k_{1 P}$, $k_{2 P}, k_{3 P}, k_{d P}$ are the constants used for carbohydrate and protein production rates within biofilm of AOC consuming bacteria, respectively; $S_{\mathrm{Cl}}^{\text {tot }}$ denotes the total disinfectant concentration (chlorine/chloramine); $k_{h}$ is the $S_{A O C}$ hydrolysis rate constant.

Note that the processes (18)-20) are only considered in the case of AOC consuming bacteria. Moreover, by assumption the processes (10), (11), (13), (15) and (17)-119) are not considered in the case of the tank reactions.

\section{Model structure}

The quality model derived in this work is conceptually divided into two main substructures representing the chemical reactions of the DWDS and the biological regrowth (Fig. 11).

The quality of water entering the DWDS as well as changes in the transportation mechanism constitute the disturbance inputs. Both are denoted by bold arrows entering the structure. The state variables are the concentrations of the chemical and biological species considered in the model. Two distinct types of outputs are to be defined. The first one constitutes the model state.

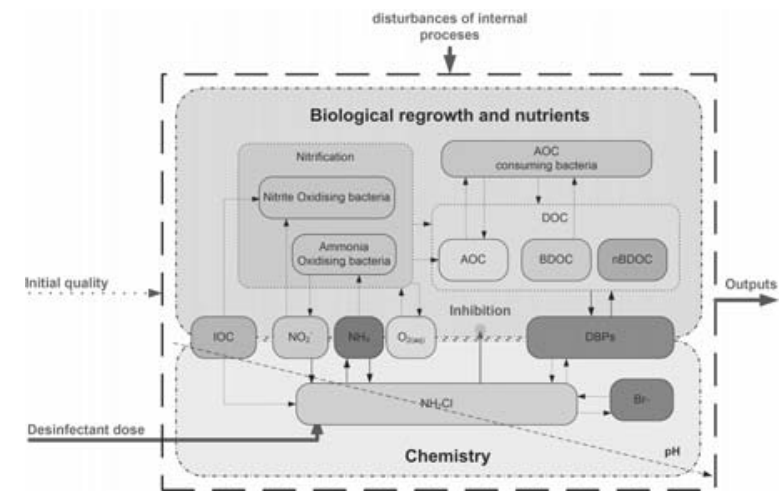

Fig. 1. DWDS quality model structure.

The second is the so-called technological output vector built-up of aggregated measurement accessible quantities (total chlorine, total DBPs, total biomass, alkalinity and $\mathrm{pH})$. Both are designated by bold line arrows leaving the structure. A dotted line arrow entering this structure represents the initial quality state of the model. A dashed line arrow crossing the structure indicates the $\mathrm{pH}$ variability.

The core element of the chemical module is the chloramine decay model and its related interactions resulting from bromine catalysis and reactions with nitrogen compounds. The biological model substructure consists of both heterotrophic (AOC consuming bacteria) and chemo-autotrophic bacteria species (Ammonia Oxidizing Bacteria (AOB; Nitrosomonas), and Nitrite Oxidizing Bacteria (NOB; Nitrobacter)). The latter are responsible for nitrification processes and their presence in the model is due to chloramine (the source of nitrogen) chosen as disinfectant. The interaction layer constitutes mainly of nutrients and growth limiting chemical/biochemical substances for the biological regrowth model and above all DBPs formation processes. The knowledge of the latter is considered crucial for proper DWDS quality control.

For the legibility of concept presentation, the DWDS quality model structure illustrated in Fig. 1 is given for a single flow independent time-space point of a DWDS pipe. The full scale quality model formulation is introduced in Section 4

\section{Model formulation}

4.1. Chemical module. Applying chemical engineering theory (Section 2.1) to modelling practice is not a trivial task due to the nonlinear nature of phenomena and their time-varying parameter dependencies such as temperature and $\mathrm{pH}$ (cf., e.g., Pope, 2006).

In this work effort is made to a build dynamic (kinetic) model describing these dependencies. Although aqueous chemistry regarding the species of interest 
(Section 3) was investigated in the past (Section 1) not all the works aim at quantifying these relationships towards obtaining a dynamic model. The main contributors to this section are Vikesland et al. (2001) and Duirk et al. (2002).

Note that in aqueous chemistry the dissociation reactions fall under this category due to their fast reaction rates, undeniably faster than other processes. Nevertheless, a consequence of steady-state approximation is a certain structure error. Therefore caution is required.

In the following, formulations of the chemical sub-modules considered (Section 3) are given.

Chloramine. The aqueous chloramines reaction set (Vikesland et al., 2001) is given by

$$
\begin{aligned}
& \mathrm{HOCl}+\mathrm{NH}_{3} \stackrel{k_{C l 1}}{\longrightarrow} \mathrm{NH}_{2} \mathrm{Cl}+\mathrm{H}_{2} \mathrm{O}, \\
& \mathrm{NH}_{2} \mathrm{Cl}+\mathrm{H}_{2} \mathrm{O} \stackrel{k_{C l 2}}{\longrightarrow} \mathrm{NOCl}+\mathrm{NH}_{3}, \\
& \mathrm{HOCl}+\mathrm{NH}_{2} \mathrm{Cl} \stackrel{k_{\mathrm{Cl} 3}}{\longrightarrow} \mathrm{NHCl}_{2}+\mathrm{H}_{2} \mathrm{O}, \\
& \mathrm{NHCl}_{2}+\mathrm{H}_{2} \mathrm{O} \stackrel{k_{\mathrm{Cl} 4}}{\longrightarrow} \mathrm{HOCl}+\mathrm{NH}_{2} \mathrm{Cl} \text {, } \\
& 2 \mathrm{NH}_{2} \mathrm{Cl} \stackrel{k_{\mathrm{Cl} l 5}}{\longrightarrow} \mathrm{NHCl}_{2}+\mathrm{NH}_{3}, \\
& \mathrm{NHCl}_{2}+\mathrm{NH}_{3} \stackrel{k_{\mathrm{Cl} l}}{\longrightarrow} 2 \mathrm{NH}_{2} \mathrm{Cl} \text {, } \\
& \mathrm{NHCl}_{2}+\mathrm{H}_{2} \mathrm{O} \stackrel{k_{\mathrm{Cl} l}}{\longrightarrow} \mathrm{I}+2 \mathrm{HCl}, \\
& \mathrm{I}+\mathrm{NHCl}_{2} \stackrel{k_{\mathrm{Cl} 8}}{\longrightarrow} \mathrm{HOCl}+\mathrm{N}_{2}+\mathrm{HCl}, \\
& \mathrm{I}+\mathrm{NH}_{2} \mathrm{Cl} \stackrel{k_{\mathrm{Cl9}}}{\longrightarrow} \mathrm{N}_{2}+\mathrm{H}_{2} \mathrm{O}+\mathrm{HCl}, \\
& \mathrm{NH}_{2} \mathrm{Cl}+\mathrm{NHCl}_{2} \stackrel{k_{\mathrm{Cl1}}}{\longrightarrow} \mathrm{N}_{2}+3 \mathrm{HCl},
\end{aligned}
$$

where the reaction kinetic constants are as follows: $k_{C l 1}=1.5 \cdot 10^{10} M^{-1} h^{-1}, k_{C l 2}=7.6 \cdot 10^{-2} h^{-1}$ (Morris and Isaac, 1981), $k_{C l 3}=1.0 \cdot 10^{6} M^{-1} h^{-1}$, $k_{C l 4}=2.3 \cdot 10^{-3} h^{-1}$ (Margerum et al., 1978), $k_{C l 5}=$ $k_{\mathrm{Cl5,1}, 1}\left[\mathrm{H}^{+}\right]+k_{\mathrm{Cl5,2}}\left[\mathrm{H}_{2} \mathrm{CO}_{3}\right]+k_{\mathrm{Cl5}, 3}\left[\mathrm{HCO}_{3}^{-}\right]$with $k_{C l 5,1}=4.0 \cdot 10^{4} M^{-2} h^{-1}, k_{C l 5,2}=8 \cdot 10^{2} M^{-2} h^{-1}$, $k_{C l 5,3}=2.5 \cdot 10^{7} M^{-2} h^{-1}$ (Vikesland et al., 2001), $k_{C l 6}=2.2 \cdot 10^{8} M^{-2} h^{-1}$ (Hand and Margerum, 1983), $k_{C l 7}=4.0 \cdot 10^{5} M^{-1} h^{-1}$ (Jafvert and Valentine, 1987), $k_{C l 8}=1.0 \cdot 10^{8} M^{-1} h^{-1}, k_{C l 9}=3.0 \cdot 10^{7} M^{-1} h^{-1}$, $k_{C l 10}=55.0 M^{-1} h^{-1}$ (Leao, 1981).

The resulting disinfectant (chloramine) sub-module (Fig. 1) is represented by state vector $\mathbf{C}_{C l}(t)$ defined as

$$
\begin{aligned}
\mathbf{C}_{C l}(t) \triangleq & {\left[[\mathrm{HOCl}]+\left[\mathrm{OCl}^{-}\right],\left[\mathrm{NH}_{3}\right]+\left[\mathrm{NH}_{4}^{+}\right],\right.} \\
& {\left.\left[\mathrm{NH}_{2} \mathrm{Cl}\right]+\left[\mathrm{NH}_{3} \mathrm{Cl}^{+}\right],\left[\mathrm{NHCl}_{2}\right],[\mathrm{II}]\right]^{T}, }
\end{aligned}
$$

where monochloramine $\left[\mathrm{NH}_{2} \mathrm{Cl}\right]$, dichloramine $\left[\mathrm{NHCl}_{2}\right]$, their cations $\left[\mathrm{NH}_{3} \mathrm{Cl}\right]$ and hypochlorous $[\mathrm{HOCl}]$ acid as well as $\left[\mathrm{OCl}^{-}\right]$ions constitute the group of disinfecting species, $\left[\mathrm{NH}_{3}\right]$ denotes ammonia, $\left[\mathrm{NH}_{4}^{+}\right]$ represents ammonia cations, $[I]$ is an artificial compound.

The disinfectants are formed in a set of dichloramine decay reactions where at each stage chlorine reduction occurs. Two exceptions are hypochlorous ions and dichloramines cations. The former are a result of dissociation of hypochlorous acid. The latter result of the absorption of dissolved protons. The dichloramines are formed in the reaction of disproportion of monochloramine. The omitted reactions paths are compensated within the overbalance by introducing the artificial compound $[I]$ (Vikesland et al., 2001).

Hydrogen ions. (Accounting for $p H$ variability) To account for the $\mathrm{pH}$ changes in the DWDS environment, a hydrogen ion count was implemented. Due to different speeds of contributing reactions, an equilibrium model was proposed as in the work of Snoeyink and Jenkins (1980). It consists of the following dissociation reactions:

$$
\begin{aligned}
& \mathrm{HOCl} \stackrel{K_{1}}{\rightleftarrows} \mathrm{H}^{+}+\mathrm{OCl}^{-}, \\
& \mathrm{NH}_{4}^{+} \stackrel{K_{2}}{\rightleftarrows} \mathrm{NH}_{3}+\mathrm{H}^{+}, \\
& \mathrm{H}_{2} \mathrm{CO}_{3} \stackrel{K_{3}}{\rightleftarrows} \mathrm{HCO}_{3}^{-}+\mathrm{H}^{+} \text {, } \\
& \mathrm{HCO}_{3}^{-} \stackrel{K_{3}}{\rightleftarrows} \mathrm{CO}_{3}^{2-}+\mathrm{H}^{+},
\end{aligned}
$$

where $K_{1}=10^{-7.5} M^{-1}, K_{2}=10^{-9.3} M^{-1}, K_{3}=$ $10^{-6.3} M^{-1}, K_{4}=10^{-10.3} M^{-1}$ (Snoeyink and Jenkins, 1980).

Although this group does not introduce explicitly new state variables, implicitly an assumption on the existence of a state variable defined by $\mathbf{C}_{H}$ arises:

$$
\begin{aligned}
\mathbf{C}_{H} \triangleq & {\left[\left[\mathrm{H}_{r}^{+}\right],\left[\mathrm{H}_{2} \mathrm{CO}_{3}\right]+\left[\mathrm{HCO}_{3}^{-}\right]+\right.} \\
& \left.+\left[\mathrm{CO}_{3}^{2-}\right], 2\left[\mathrm{Ca}^{2+}\right]+\text { other }\right]^{T},
\end{aligned}
$$

where $\left[H_{r}^{+}\right]$are the hydrogen ions resulting from reactions, $\left[\mathrm{H}_{2} \mathrm{CO}_{3}\right], \quad\left[\mathrm{HCO}_{3}^{-}\right],\left[\mathrm{CO}_{3}^{2-}\right]$ represent carbonates, $\left[\mathrm{Ca}^{2+}\right]+$ other denotes cations of carbonate species.

Since it would be hard to account for all the hydrogen ions in even the smallest DWDS, an incremental model is proposed. $\left[H_{r}^{+}\right]$denotes the difference in the number of hydrogen ions introduced due to quality processes thus resulting in $p H$ variability. The existence of the second and third state variable is required to describe the carbonate buffer resulting from the dissociation mechanism given by (32)- 35).

Inorganic carbon. The InOrganic Carbon (IOC) fraction in the model is composed of the carbonate acid and carbonate ions 36 , the second variable in $\mathbf{C}_{H}$. It 
has a broad influence on the model internal dynamics as it affects the $p H$ levels, the mechanism of disproportion reaction within the monochloramine group (25) and the bacteria assimilation processes during nitrification (Section 4.2).

Nitrogen ions. The main contributors to nitrogen ion formation are biological nitrification processes (Section 4.2). Nitrogen ions are responsible for decomposition of chloramines and, by doing so, for disrupting the their disinfection potential. This is why the concentration of this species should be kept as low as possible to prevent biological instability. Keeping track of this group's behaviour is one of the crucial indicators during the development of DWDS control strategies.

The nitrogen ions reaction paths are as follows (Vikesland et al., 2001):

$$
\begin{gathered}
\mathrm{H}^{+}+\mathrm{NH}_{2} \mathrm{Cl}+\mathrm{NO}_{2}^{-} \longrightarrow \mathrm{NH}_{3}+\mathrm{NO}_{2} \mathrm{Cl}, \\
\mathrm{NH}_{3}+\mathrm{NO}_{2} \mathrm{Cl} \longrightarrow \mathrm{H}^{+}+\mathrm{NH}_{2} \mathrm{Cl}+\mathrm{NO}_{2}^{-} \\
\mathrm{NO}_{2} \mathrm{Cl}+\mathrm{NO}_{2}^{-} \longrightarrow \mathrm{N}_{2} \mathrm{O}_{4}+\mathrm{Cl}^{-}, \\
\mathrm{N}_{2} \mathrm{O}_{4}+\mathrm{Cl}^{-} \longrightarrow \mathrm{NO}_{2} \mathrm{Cl}+\mathrm{NO}_{2}^{-}, \\
\mathrm{N}_{2} \mathrm{O}_{4}+\mathrm{OH}^{-} \longrightarrow \mathrm{NO}_{3}^{-}+\mathrm{NO}_{2}^{-}+\mathrm{H}^{+}, \\
\mathrm{NO}_{2} \mathrm{Cl} \longrightarrow \mathrm{NO}_{2}^{+}+\mathrm{Cl}^{-}, \\
\mathrm{NO}_{2}^{+}+\mathrm{Cl}^{-} \longrightarrow \mathrm{NO}_{2} \mathrm{Cl}, \\
\mathrm{NO}_{2}^{+}+\mathrm{OH}^{-} \longrightarrow \mathrm{NO}_{3}^{-}+\mathrm{H}^{+},
\end{gathered}
$$

Due to limited knowledge of the kinetic constants, a steady state approximation has been utilised as in the work of Vikesland et al. (2001). The integrated reaction rate is

$$
\begin{aligned}
R^{N}= & k_{N 1}\left[\mathrm{NO}_{2}^{-}\right]\left[\mathrm{H}^{+}\right]\left[\mathrm{NH}_{2} \mathrm{Cl}\right] \\
& \times \frac{\left[\mathrm{NO}_{2}^{-}\right] k_{N 2}+1}{k_{N 3}\left[\mathrm{NH}_{3}\right]+k_{N 2}\left[N \mathrm{~N}_{2}^{-}\right]+1},
\end{aligned}
$$

where $R^{N}$ denotes the aggregated nitrogen group reaction rate with the following set of constants: $k_{N 1}=4.90$. $10^{10} M^{-2} h^{-1}, k_{N 2}=217 M^{-1}$ (Margerum et al., 1994), $k_{N 3}=5.5 \cdot 10^{5} M^{-1}$ (Johnson and Margerum, 1991).

In consequence, a new state variable $\mathbf{C}_{N}$ is introduced:

$$
\mathbf{C}_{N} \triangleq\left[N O_{2}^{-}\right]
$$

Incorporating nitrogen ions into the model structure enables keeping track not only of the normal, but also of disturbance operational condition (Section 3).
Bromine ions. Bromine ions constitute catalysing species for the chloramine decomposition. The set of reactions paths considered for this group is as follows:

$$
\begin{aligned}
& \mathrm{NH}_{2} \mathrm{Cl}+\mathrm{H}^{+} \stackrel{K_{B r 1}}{\rightleftharpoons} \mathrm{NH}_{3} \mathrm{Cl}^{+}, \\
& \mathrm{NH}_{3} \mathrm{Cl}^{+}+\mathrm{Br}^{-} \stackrel{k_{\mathrm{Br1}}}{\longrightarrow} \mathrm{NH}_{2} \mathrm{Br}+\mathrm{Cl}^{-}+\mathrm{H}^{+}, \\
& \mathrm{NH}_{2} \mathrm{Cl}+\mathrm{NH}_{3} \mathrm{Br}^{+} \stackrel{\text { fast }}{\longrightarrow} \mathrm{NHBrCl}+\mathrm{NH}_{4}^{+} \text {, } \\
& \mathrm{HOCl}+\mathrm{Br}^{-} \stackrel{k_{B r 2}}{\longrightarrow} \mathrm{HOBr}+\mathrm{Cl}^{-}, \\
& \mathrm{HOBr}+\mathrm{NH}_{2} \mathrm{Cl} \stackrel{k_{\mathrm{Br} 3}}{\longrightarrow} \mathrm{NHBrCl}+\mathrm{H}_{2} \mathrm{O}, \\
& \mathrm{OBr}^{-}+\mathrm{NH}_{2} \mathrm{Cl} \stackrel{k_{\mathrm{Br} 4}}{\longrightarrow} \mathrm{NHBrCl}+\mathrm{OH}^{-}, \\
& \mathrm{NHBrCl}+\mathrm{NH}_{2} \mathrm{Cl} \stackrel{\text { fast }}{\longrightarrow} \mathrm{N}_{2}+\mathrm{Br}^{-}+2 \mathrm{Cl}^{-}+3 \mathrm{H}^{+} \text {, } \\
& \mathrm{HOBr} \stackrel{K_{B r 2}}{\rightleftarrows} \mathrm{OBr} r^{-}+H^{+},
\end{aligned}
$$

where $k_{B r 1}=1.8 \cdot 10^{8} M^{-1} h^{-1}$ (Trofe et al., 1980), $k_{B r 2}=5.1 \cdot 10^{5} M^{-1} h^{-1}$ (Bousher et al., 1986), $k_{B r 3}=$ $7.92 \cdot 10^{7} M^{-1} h^{-1}, k_{B r 4}=1.03 \cdot 10^{9} M^{-1} h^{-1}, K_{B r 2}=$ $M^{-1}$ (Gazda and Margerum, 1994), $K_{B r 1}=28 M^{-1}$ (Gray et al., 1978).

The corresponding state vector $\mathbf{C}_{B r}$ is defined as

$$
\mathbf{C}_{B r} \triangleq\left[\left[B r^{-}\right],[H O B r]+\left[O B r^{-}\right]\right]^{T} .
$$

The bromine ions are considered to be persistent species having a catalytic effect on the decay of monochloramine. It is assumed that their concentration depends on the quality of water entering the DWDS and, as such it regarded to be a disturbance input.

Finally, the chemical module of the derived model is described by a state vector $\mathbf{C}_{C h}$ defined as

$$
\mathbf{C}_{C h} \triangleq\left[\mathbf{C}_{C l}^{T}, \mathbf{C}_{H}^{T}, \mathbf{C}_{N}^{T}, \mathbf{C}_{B r}^{T}\right]^{T} .
$$

The presented chemical module in its current shape omits the reactions with the pipe walls.

4.2. Biological regrowth. In order to specify the biological regrowth model (Section 3.2), $\gamma$ needs to be identified. Therefore, $\gamma \in \Gamma$ and $\Gamma \triangleq$ $\{A O C, A O B, N O B\}$. Moreover, for each $\gamma$ the specific growth and death rates need to defined, which will be done in the sequel.

AOC consuming bacteria. Heterotrophic bacteria species (assumed to consume AOC) follow the general mechanisms given in Section 2.3 acquired from Jegatheesan et al. (2003). To specify this general mechanism, the specific growth rates $\left(\mu_{s p e c}^{\gamma}\right.$ and $\left.\mu_{\text {spec-bio }}^{\gamma}\right)$ and death rates $\left(\mu_{\text {death }}^{\gamma}\right.$ and $\left.\mu_{\text {death-bio }}^{\gamma}\right)$ need to be defined for both planktonic and biofilm forms. 
Based on Jegatheesan et al. (2003), with $\gamma=A O C$, $\mu_{\text {spec }}^{A O C}$ and $\mu_{\text {spec-bio }}^{A O C}$ are given as follows:

$$
\begin{gathered}
\mu_{\text {spec }}^{A O C} \triangleq \frac{\mu_{\max }^{A O C}}{k_{g C l} S_{C l}^{t o t}} \frac{S_{A O C}}{S_{A O C}+K_{A O C}}, \\
\mu_{\text {spec-bio }}^{A O C} \triangleq \frac{\mu_{\text {max }-b i o}^{A O C}}{k_{g C l} S_{C l}^{t o t}} \frac{S_{A O C}}{S_{A O C}+K_{A O C}},
\end{gathered}
$$

where $\mu_{\max }^{A O C}$ and $\mu_{\max -b i o}^{A O C}$ are the maximum growth rates of bulk and biofilm species, respectively, and $\mu_{\max }^{A O C}=0.528 d^{-1}, \mu_{\max -b i o}^{A O C}=0.0528 d^{-1}$ (Jegatheesan et al., 2003), $S_{A O C}$ is the assimilable organic carbon concentration in $[\mathrm{mg}-\mathrm{C} / \mathrm{L}], K_{A O C}$ is the half-saturation constant and $K_{A O C}=0.1 \mathrm{mg}-\mathrm{C} / \mathrm{L}, k_{g C l}$ is the inhibition kinetic constant due to disinfection and $k_{g C l}=1.5 \mathrm{~L} / \mathrm{mg}-\mathrm{Cl}, S_{C l}^{t o t}$ is the total disinfectant in $[\mathrm{mg}-\mathrm{Cl} / \mathrm{L}]$, whereas $\mu_{\text {death }}^{A O C}$ and $\mu_{\text {death-bio }}^{A O C}$ are defined as

$$
\begin{aligned}
\mu_{\text {death }}^{A O C \triangleq} & \left(k_{m}+k m C l S_{C l}^{t o t}\right) \\
& \times \exp \left(-\frac{k_{m A O C} S_{A O C}}{S_{A O C}+K_{m A O C}}\right), \\
\mu_{\text {death-bio }}^{A O C} \equiv & \mu_{\text {death }}^{A O C},
\end{aligned}
$$

where $k_{m}, k_{m C l}, K_{m A O C}$ and $k_{m A O C}$ are kinetic constants building up the bacteria death rate and $k_{m}=$ $0.04 d^{-1}, k_{m C l}=0.25 \cdot k_{m}, K_{m A O C}=0.5 \mathrm{mg}-\mathrm{C} / \mathrm{L}$, $k_{m A O C}=1.0$. To complete the specification, the following set of constants (Jegatheesan et al., 2003) needs to be in place: $k_{a}^{A O C}=0.00082 d^{-1}, k_{d}^{A O C}=$ $0.00097 d^{-1}, \quad k_{l}^{A O C}=0.01 d^{-1}, \quad k_{1 C}=6.3$. $10^{-7} \mathrm{~m}^{3} \mathrm{~d}^{-1}, k_{2 C}=27.3, k_{3 C}=0.055 \mathrm{~m}^{3} \mathrm{~g}^{-1}, k_{d C}=$ $1.43 \mathrm{~g} \cdot \mathrm{m}^{-2} d^{-1}, k_{1 p}=5.81 \cdot 10^{-8} \mathrm{~m}^{3} d^{-1}, k_{2 p}=8.54$, $k_{3 p}=41.5 \mathrm{~m}^{3} \mathrm{~g}^{-1}, k_{d p}=9.92 \mathrm{~g} \cdot \mathrm{m}^{-2} \mathrm{~d}^{-1}, k_{h}=$ $1 \cdot 10^{-12} \mathrm{~g} \cdot$ cell $^{-1} \mathrm{~d}^{-1}, X_{\text {sat }}^{A O C}=4 \cdot 10^{10}$ cells $\cdot \mathrm{m}^{-2}$, $X_{D 0}^{A O C}=0$ cells $\cdot m^{-3} d^{-1}, X_{D b 0}^{A O C}=0$ cells $\cdot m^{-2} d-1$.

The contribution of the regarded bacteria group to the global state vector is as follows:

$$
\begin{aligned}
C_{X}^{A O C} \triangleq & {\left[X_{L}^{A O C}, X_{L b}^{A O C}, X_{D}^{A O C},\right.} \\
& \left.X_{D b}^{A O C}, X_{c}^{A O C}, X_{p}^{A O C}\right]^{T} .
\end{aligned}
$$

Ammonia and nitrate oxidizing bacteria. The specific growth rates characterising the $\mathrm{AOB}$ and NOB species ( $\gamma=A O B$ and $\gamma=N O B$ respectively) are as follows (Liu et al., 2005a; 2005b):

$$
\begin{aligned}
\mu_{\text {spec }}^{A O B} \triangleq & \mu_{\max }^{A O B} \frac{S_{N H 3}}{S_{N H 3}+K_{N H 3}} \\
& \times \frac{K_{N H 2 C l}}{K_{N H 2 C l}+S_{N H 2 C l}} \frac{S_{D O}}{K_{O 2}+S_{D O}}, \\
\mu_{\text {spec-bio }}^{A O B} \triangleq & \mu_{\max -b i o}^{A O B} \frac{S_{N H 3}}{S_{N H 3}+K_{N H 3}} \\
& \times \frac{K_{N H 2 C l}}{K_{N H 2 C l}+S_{N H 2 C l}} \frac{S_{D O}}{K_{O 2}+S_{D O}},
\end{aligned}
$$

$$
\begin{aligned}
\mu_{\text {spec }}^{N O B} \triangleq & \mu_{\max }^{N O B} \frac{S_{N O 2}}{S_{N O 2}+K_{N O 2}} \\
& \times \frac{K_{N H 2 C l}}{K_{N H 2 C l}+S_{N H 2 C l}} \frac{S_{D O}}{K_{O 2}+S_{D O}}, \\
\mu_{\text {spec }- \text { bio }}^{N O B} \triangleq & \mu_{\text {max }- \text { bio }}^{N O B} \frac{S_{N O 2}}{S_{N O 2}+K_{N O 2}} \\
& \times \frac{K_{N H 2 C l}}{K_{N H 2 C l}+S_{N H 2 C l}} \frac{S_{D O}}{K_{O 2}+S_{D O}},
\end{aligned}
$$

where $\mu_{\max }^{A O B}, \mu_{\max _{b} i o}^{A O B}, \mu_{\max }^{N O B}, \mu_{\max -b i o}^{N O B}$ are the maximum planktonic and biofilm growth rates for $\mathrm{AOB}$ and NOB bacteria and $\mu_{\max -b i o}^{A O B}=0.4 d^{-1}$ (Antonious, 1989), $\mu_{\max -\text { bio }}^{N O B}=0.55 d^{-1}$ (Metcalf et al., 1978), $\mu_{\max }^{A O B}=10 \mu_{\max -b i o}^{A O B}, \mu_{\max -\text { bio }}^{N O B}=10$ (Jegatheesan et al., 2003), $S_{N H 3}$ is the ammonia concentration in [mgN/L], $K_{N H 3}$ is the ammonia half-saturation constant and $K_{N H 3}=0.2 \mathrm{mg}-\mathrm{N} / \mathrm{L}$ (Antonious, 1989), $S_{\mathrm{NH} 2 \mathrm{Cl}}$ is chloramines concentration in $[\mathrm{mg} \mathrm{Cl} / \mathrm{L}], K_{N H 2 C l}$ is the chloramines half-saturation constant and $\mathrm{K}_{\mathrm{NH} 2 \mathrm{Cl}}=$ $0.5 \mathrm{mg}-\mathrm{Cl} / \mathrm{L}$ (Liu et al., 2005a), $S_{D O}$ is the dissolved oxygen concentration in $[\mathrm{mg} / \mathrm{L}] ; K_{\mathrm{O} 2}$ is the oxygen half-saturation constant and $K_{\mathrm{O} 2}=0.4 \mathrm{mg} / \mathrm{L}$ (Williamson and McCarty, 1976); $S_{N O 2}$ is the nitrite concentration in $[\mathrm{mgN} / \mathrm{L}] ; K_{\mathrm{NO} 2}$ is the nitrite half-saturation constant and $K_{N O 2}=1.2 \mathrm{mg}-\mathrm{N} / \mathrm{L}$ (Metcalf et al., 1978).

It is assumed that the die-off mechanism of $\mathrm{AOB}$ and NOB species is analogous to the case of AOC species. The same assumption holds for kinetic constants related to the mechanisms such as attachment, detachment etc.

Introducing $\mathrm{AOB}$ and $\mathrm{NOB}$ bacteria species requires defining the following state vectors:

$$
\begin{gathered}
\mathbf{C}_{X}^{A O B} \triangleq\left[X_{L}^{A O B}, X_{L b}^{A O B}, X_{D}^{A O B}, X_{c}^{A O B}, X_{p}^{A O B}\right]^{T}, \\
\mathbf{C}_{X}^{N O B} \triangleq\left[X_{L}^{N O B}, X_{L b}^{N O B}, X_{D}^{N O B}, X_{c}^{N O B}, X_{p}^{N O B}\right]^{T} .
\end{gathered}
$$

Finally, the following holds:

$$
\mathbf{C}_{B i o} \triangleq\left[\mathbf{C}_{X}^{A O C^{T}}, \mathbf{C}_{X}^{A O B^{T}}, \mathbf{C}_{X}^{N O B^{T}}\right]^{T}
$$

4.3. Biochemical interactions. The interactions between the chemical and biological modules within the model constitute the biochemical interface layer (see Section 3). This specific group consists of all substrates utilised by bacteria as nutrients as well as the substances limiting their growth and those being the products of biochemical reactions catalysed by bacteria.

Inhibition. The inhibition process limits the bacterial growth by blocking the transportation mechanisms of nutrients into their cells. The rate of this process is controlled by the disinfectant concentration levels. It is considered to be a control input of the DWDS quality model to be exploited by the control algorithms 
being derived. During this process, chlorine/chloramines concentration is not directly affected. Nevertheless, by increasing the bacterial die-off the disinfectant present in the medium reacts with the organic matter released from the dead bacteria. This is why the presence of bacteria in the DWDS deteriorates the disinfectant levels. The influence of disinfectant concentration on the lifecycle of AOC, AOB and NOB bacteria species was introduced in Section 4.2 (see (57)- 60) and (62)-65).

Two step nitrification process. Since chloramine is a source of nitrogen, it serves as a nutrient source for $\mathrm{AOB}$ and NOB species. Therefore, the nitrification process is a very important interaction to account for when considering this disinfectant (Section 4.2). The implemented two-step nitrification mechanism interacts with aqueous chemistry according to Liu et al. (2005a; 2005b):

$$
\begin{gathered}
\mathrm{NH}_{3}+\mathrm{CO}_{2}+1.5 \mathrm{O}_{2} \stackrel{A O B}{\longrightarrow} \mathrm{NO}_{2}^{-}+\mathrm{H}_{2} \mathrm{O}+\mathrm{H}^{+}, \\
\mathrm{NO}_{2}^{-}+\mathrm{CO}_{2}+0.5 \mathrm{O}_{2} \stackrel{\mathrm{NOB}}{\longrightarrow} \mathrm{NO}_{3}^{-} .
\end{gathered}
$$

The AOB bacteria increase the nitrite $\left(\mathrm{NO}_{2}^{-}\right)$levels, which results in a faster decay of chloramine. This produces ammonia $\left(\mathrm{NH}_{3}\right)$ which is a nutrient for AOB species. Also NOB species are affected by increased levels of nitrite. Both bacteria species interact with the multi stage reaction of the chloramines and nitrogen group (Section 4.1). In unfavourable circumstances this can trigger positive feedback between both groups, resulting in bacterial destabilisation-transition from the normal to the disturbance operational state.

Nutrients. Nutrient count, crucial for the bacterial regrowth module, is modelled by mass balance equations. This requires the following constants to be defined: bacterial cell to carbon count $B_{1}=0.5 \cdot 10^{13}$ cell/mg-C (Bitton, 1998), volatile suspended solids (VSS) to cell count $B_{2}=3.70 \cdot 10^{9}$ cell/mg-C (McKinney, 2004)) and a set of yield coefficients: $Y_{A O C}=$ $0.2 \mathrm{mg} / \mathrm{mg}-\mathrm{C}$ (Jegatheesan et al., 2004), $Y_{N H 3}=$ $0.19 \mathrm{mgVSS} / \mathrm{mgNH}_{3}-N$ (Metcalf et al., 1978), $Y_{\mathrm{NO} 2}=$ $0.2 \mathrm{mg} \mathrm{VSS} / \mathrm{mg} \mathrm{NO}_{2}-\mathrm{N}$ (Poduska and Andrews, 1974), which determine the increase in the bacteria mass per unit of the substrate utilised. This mass balance relationships result in additional state vector elements defined as

$$
\mathbf{C}_{S u b s} \triangleq\left[S_{A O C}, S_{B D O C}, S_{n B D O C}, S_{D O}\right]^{T},
$$

where $S_{A O C}, S_{B D O C}, S_{n B D O C}$ are the assimilable organic carbon, biodegradable organic carbon and non-biodegradable organic carbon (counted as $[\mathrm{mg}-\mathrm{C} / \mathrm{L}]$ ) respectively.
Disinfection by-products. DBPs formed during drinking water chlorination/chloramination most widely addressed in the literature consist of compounds such as TriHaloMetanes (THMs), HaloAcetic Acids (HAAs), HaloAcetoNitrils (HAN) (e.g., Nokes et al., 1999; Muellner et al., 2007; Chowdhury et al., 2009; Liu and Qi, 2010). The importance of accounting for DBPs results from the impact that these compounds exert on human health. Most of them are recognised to have strong cancerogenous effects. According to Hong et al. (2008) during water chloramination the dominant DBPs formed are HAAs. The effects of dihaloacetic acids (component of HAAs) on human health have been widely discussed in the World Health Organisation (WHO) Guidelines for Drinking Water Quality report (World Health Organisation, 2005).

Modelling the HAA formation is not an easy task due to numerous reaction paths, some of which remain still non fully identified.

Hence, a simplified model based on the work of Duirk et al. (2002) was utilised for this purpose:

$$
\begin{aligned}
& \mathrm{NH}_{2} \mathrm{Cl}+\mathrm{DOC}_{r 1} \stackrel{k_{D 1}}{\longrightarrow} \text { products, } \\
& \mathrm{NH}_{2} \mathrm{Cl}+\mathrm{DOC}_{r 2} \stackrel{k_{D 2}}{\longrightarrow} \text { products, }
\end{aligned}
$$

where $D O C_{r 1}$ and $D O C_{r 2}$ denote the fast and slow reacting $\mathrm{DOC}$ fractions, respectively, $k_{D 1}=0.9$. $10^{4} M^{-1} h^{-1}$ (Duirk et al., 2002); $k_{D 2}=k_{D 2,2} p H^{2}-$ $k_{D 2,1} p H+k_{D 2,0}, k_{D 2,2}=75.89 M^{-1} h^{-1}, k_{D 2,1}=$ $-1272 M^{-1} h^{-1}, k_{D 2,0}=5389 M^{-1} h^{-1}$ are acquired as an quadratic interpolation of the results presented by Duirk et al. (2002).

In order to implement the $\mathrm{pH}$ variability, a quadratic interpolation mechanism was proposed to extend the results of (Duirk et al., 2002).

The additional state variables are as follows:

$$
\mathbf{C}_{D B P s} \triangleq\left[\left[D O C_{r 1}\right],\left[D O C_{r 2}\right],[H A A]\right]^{T},
$$

where $C_{D B P s}$ is the state vector of the DBP module, $[H A A]$ is the total molar haloacetic acids concentration.

At this point it is clear that, to couple the DBPs formation model with the overall structure, a proper fractioning mechanism is required to divide $D O C$ into $\left[D O C_{r 1}\right]$ and $\left[D O C_{r 2}\right]$, which is quite different from the fractioning required by the biological regrowth model. For the sake of legibility the mentioned mechanism is addressed in the forthcoming paragraph.

Dissolved organic carbon fractioning. Keeping model mass balance implies that the stoichiometric relationships within the model should be respected. Since both biological and biochemical species require different DOC fractioning, a proper mechanism needs to be designed. Biochemical group (DBPs formation) fractions the DOC 


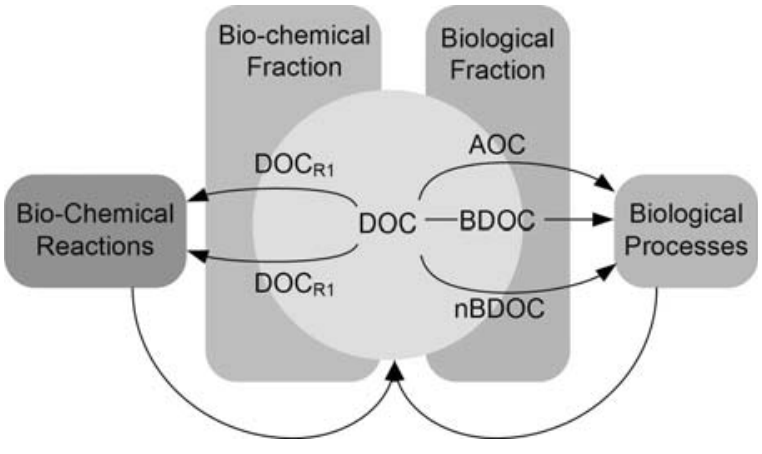

Fig. 2. DOC double-side fractioning mechanism scheme.

based on the reactivity into two groups of fast and slow reacting DOCs. The bacterial regrowth model requires that the DOC be fractioned into three groups: AOC, BDOC and nBDOC (Fig. 2). A direct implementation of this mechanism would result in obtaining a time-varying structure of DOC, which could be hard to implement. This is why the information is kept as a sum of each fraction separately with a proper balance handling mechanism in place. An assumption is made here that the newly formed compounds are proportionally distributed among the fractions according to $S_{1}$ and $S_{2}$. The consumption of DOC reduces the fraction content proportionally to their concentration according to

$$
\begin{aligned}
d_{t}\left[D O C_{r 1}\right]= & S_{1} d_{t}\left(S_{D O C}^{t o t}\right)_{+}-R_{D B P 1} \\
& -\left[D O C_{r 1}\right] S_{D O C}^{t o t}{ }^{-1} d_{t}\left(S_{D O C}^{t o t}\right)_{-}, \\
d_{t}\left[D O C_{r 2}\right]= & S_{2} d_{t}\left(S_{D O C}^{t o t}\right)_{+}-R_{D B P 2} \\
& -\left[D O C_{r 2}\right] S_{D O C}^{t o t}{ }^{-1} d_{t}\left(S_{D O C}^{t o t}\right)_{-},
\end{aligned}
$$

where $S_{1}=1.66 \cdot 10^{-1} \mathrm{~mol} / \mathrm{mg}, S_{2}=1.25 \cdot 10^{-5} \mathrm{~mol} / \mathrm{mg}$ (Duirk et al., 2002), $R_{D B P 1}$ and $R_{D B P 2}$ are the (72) and (73) reaction rates, respectively, $S_{D O C}^{t o t}$ is a sum of the DOC mass $[\mathrm{mg} / \mathrm{l}], d_{t}\left(S_{D O C}^{t o t}\right)_{-}$and $d_{t}\left(S_{D O C}^{t o t}\right)_{+},[\mathrm{mg} / \mathrm{h}]$, are the positive and negative variations in chemical DOC fractioning exerted by the bacterial regrowth module.

Finally, the following holds:

$$
\mathbf{C}_{\text {Inter }} \triangleq\left[\mathbf{C}_{D B P s}^{T}, \mathbf{C}_{\text {Subs }}^{T}\right]^{T},
$$

where $C_{\text {Inter }}$ is the interaction state vector.

4.4. Model internal state, inputs and outputs. Since by now all the modules have been introduced, a proper definition of the state vector, inputs and outputs is possible.

Let us start by defining a single space point quality vector:

$$
\mathbf{C} \triangleq\left[\mathbf{C}_{C h}^{T}, \mathbf{C}_{\text {Bio }}^{T}, \mathbf{C}_{\text {Inter }}^{T}\right]^{T} \text {. }
$$

The derived model output is composed of two parts. The first is the part given by the internal state. The second are the technological outputs that aggregate the internal process:

$$
\Upsilon \triangleq\left[\Upsilon_{\text {state }}^{T}, \boldsymbol{\Upsilon}_{\text {tech }}^{T}\right]^{T},
$$

where

$$
\Upsilon_{\text {state }} \equiv \mathbf{C}
$$

and

$$
\mathbf{\Upsilon}_{\text {tech }} \triangleq\left[S_{C l}^{t o t}, S_{D B P s}, S_{X}, S_{D O C}, A l k, p H\right]^{T},
$$

$S_{C l}^{t o t}$ is the total chlorine concentration, in $[\mathrm{mg} \mathrm{Cl} / \mathrm{L}]$, calculated as a sum of all chlorine ions at the first oxidation level, $S_{D B P s}$ is the total disinfection by-products concentration in $[\mathrm{mg} \mathrm{Cl} / \mathrm{L}], S_{X}$ is the total biomass concentration in bulk flow $[\mathrm{mg} \mathrm{C} / \mathrm{L}], S_{D O C}$ is the dissolved organic carbon concentration in $[\mathrm{mg} \mathrm{C} / \mathrm{L}]$, $A l k$ is alkalinity calculated as $A l k=\left[\mathrm{HCO}_{3}-\right]+$ $2\left[\mathrm{CO}_{3}^{2}-\right]+\left[\mathrm{NH}_{3}\right]$. There are two types of inputs. The first one is the control input which is the dosing of the disinfectant. The second one is the disturbance input, in the form of water quality entering the DWDS.

The overall model can be formulated by taking Eqns. (1) and (2) with definitions of processes presented in Sections 4.14 .3 (according to general mechanisms given in Section 2) and (75-81) combined with the hydraulic model given, e.g., by Brdys and Ulanicki (1994).

\section{Note on uncertainty}

In this section a brief introduction of key elements that contribute to the model uncertainty levels is made. Some preliminary hints on model parameter identification are given as well.

Chemical module uncertainty results in general from reaction path determination. Even a single chemical reaction may consist of a series of transformations (e.g., Deborae and von Guten, 2008). Determining these requires usually well prepared laboratory experiments. Finding a unique solution is not guaranteed as these mechanisms strongly depend on the environmental conditions such as temperature and $\mathrm{pH}$. In chemical engineering, when the reactions are very fast or their paths are not well identified, a steady state (equilibrium) approximation (based on the reaction rates) is usually applied. As a result, a simplified model structure is obtained. Although the resulting model is easier to handle both analytically and computationally, it comes at the cost of introducing additional uncertainty. Nevertheless, coupled handling of this simplified structure along with remaining dynamic equations still enables the model to work in a wide range of conditions with only some imprecision during a rather short period of transients due to differences in time constants. Therefore, factors 
influencing the uncertainty of the chemical module result from the structural error due to omitted reaction paths (considered unknown according to the state of the art), equilibrium simplifications and neglected temperature effects. This is also the case of the biochemical part, namely, DBPs.

In the case of the biological module, the Monod kinetic model was applied. The advantage is that it remains less computationally demanding (in the context of DWDS environment simulation) than the precise cell models of life processes (e.g., Myszor and Cyran, 2013). However, this comes at the cost of structural uncertainty and has also a consequence for parameter identification.

Regarding the parameter identification, two different approaches can be applied: to perform a laboratory test to determine precise structure and identify its parameters (e.g., Vikesland et al., 2001), to propose the structure a priori and then tune its parameters (e.g., Clark et al., 2002). This results in white and grey box models, respectively. The derived chemical module is composed of a hybrid of both these types. Therefore, parameter tuning is actualy crucial in the case of sub-modules of the latter type. The biological module is represented by models derived based on the second approach. Therefore, parameter identification should be performed for each DWDS individually (e.g., LeChevallier et al., 1996). Since a DWDS is usually distributed over a large area, to obtain a more accurate model, one can consider the parameter identification process to be performed regionally throughout a given DWDS.

To decrease the level of uncertainty in the derived model parameter values, an extensive literature study was conducted to acquire parameters from works with rich experimental background.

\section{Simulation experiments}

In this section two numerical examples are given to illustrate the model behaviour in normal and disturbance operational conditions. The latter is considered to occur due to bacteriological instability.

Example 1. This example illustrates the model behaviour during the DWDS (Fig. 3) normal operation. To reduce the influence of the initial conditions, the results shown in this experiment are displayed after the period of around 20 days of simulation. In Fig. 4 the time trajectories of the total chlorine $S_{C l-t o t}$, disinfection by-products $D B P s$, the total biomass $X$ and $\mathrm{pH}$ for two distinct disinfection scenarios are given.

The two scenarios are characterised by constant chloramine dosing at the level of $S_{\mathrm{N} 2 \mathrm{Cl}}=1.7 \mathrm{mg}-\mathrm{Cl} / \mathrm{L}$ and $S_{N H 2 C l}=0.34 \mathrm{mg}-\mathrm{Cl} / \mathrm{L}$, respectively. The injection point is the network node 1 (Fig. 3). The higher disinfectant dosing profiles are clearly visible in the total

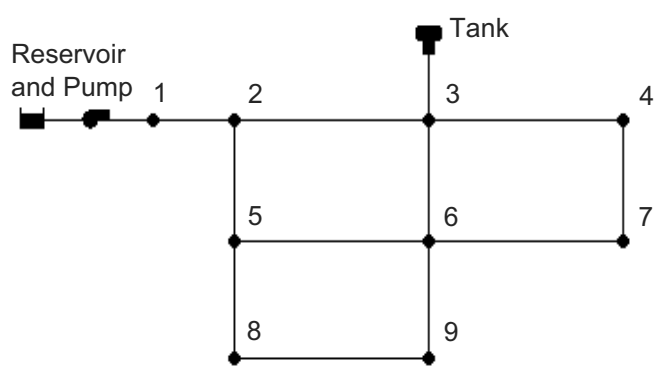

Fig. 3. EPANET DWDS layout example.
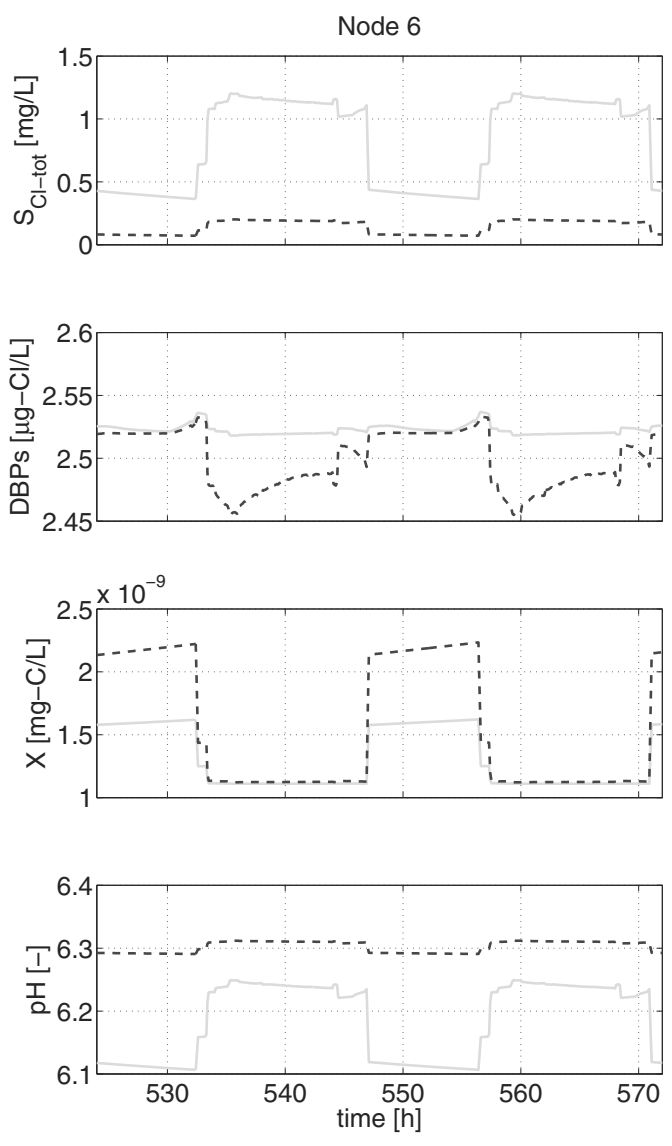

Scenario 1 - - - Scenario 2

Fig. 4. Normal operational conditions.

chlorine and DBPs trajectories. The considerable increase in the concentration of the latter is clearly visible (Fig. 4). On the other hand, an increase in disinfectant levels lowers the total biomass concentration due to inhibition. The variations in $p H$ levels are due to changes in oxidising properties of the disinfectant. The obtained results are consistent with the experimental knowledge reported in the literature.

In all the plots (Fig. 4) the abrupt changes in the trajectories illustrate the impact of the transportation 
mechanism (mainly tank operation).

Example 2. This example illustrates bacterial instability
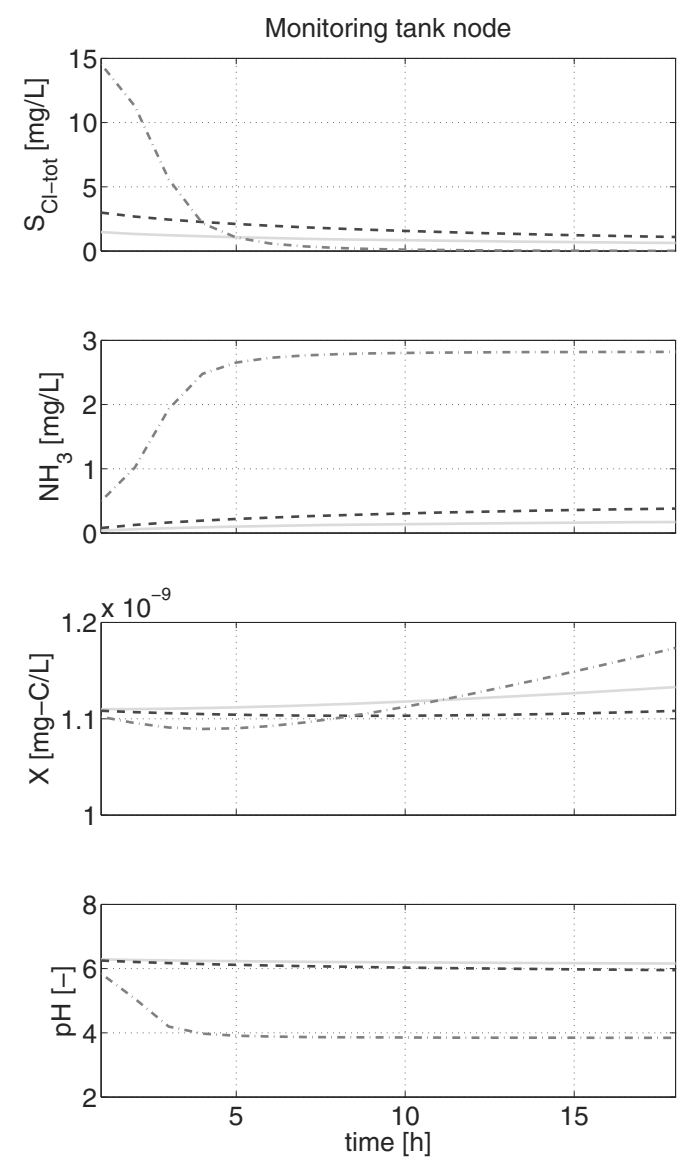

Scenario 1 - --Scenario 2 - - Nitrification

Fig. 6. Bacterial instability within Gdynia DWDS.

within the Gdynia DWDS (Fig. 5) due to a nitrification event based on the tank quality measurements. For comparison, the nitrification results are plotted against the ones obtained with the input scenarios 1 and 2 . The chlorine input node and the monitoring node are indicated in Fig. 5

In Fig. 6] a comparison of disinfectant decomposition is shown. Although the initial concentration of disinfectant in the current trial was higher than in Example 1 it was swiftly decreased to an even lower level. This is a consequence of newly triggered processes of nitrification being a part of the model internal dynamics.

As illustrated in Fig. 6, the first step of the nitrification process is triggered at around the 5-th hour. At this time, ammonia concentration reaches levels high enough to accelerate multiplication of $\mathrm{AOB}$ bacterial strain. This event decreases the disinfectant concentration due to the nitrite being produced as a product of a biochemical reaction carried by $\mathrm{AOB}$ species. Nitrite causes the chloramine decay rate to accelerate, although the latter concentration in the influent water is still kept at a high level. The rate of nitrate reactions with chemical species is much faster than with NOB bacteria, which actually reduces the population of the latter. Ultimately, the significantly lowered levels of disinfectant result in triggering the AOC bacteria species to accelerate their growth as well.

In Fig. 6 a comparison of the total biomass trajectories obtained in a normal operational state against the nitrification scenario trajectory is presented. Clearly, the inhibitory effect of chloramine in the case of highly active nitrification is significantly reduced although its input concentration is kept at higher a level than in the normal operational conditions.

A consequence of the nitrification processes being triggered is the undesired (regarding DWDS operational objectives) decrease in $\mathrm{pH}$ levels (see Fig. 6).

The obtained results are consistent with the observation made during daily operation of the DWDS reported, e.g., by Liu et al. (2005a; 2005b).

This example illustrates the derived model's capabilities to handle also disturbance operational states. The experiment clearly indicated that nitrification occurrence indeed has impact on the $\mathrm{pH}$ levels that affect all the aqueous chemistry by shifting the reaction kinetics. This shows that the application of linear kinetic models with stationary parameters is not a valid solution to handle a wide range of operational states. This has a significant consequence for the development and verification of monitoring, control and security algorithms.

To conclude, two distinct simulation examples were shown to illustrate normal and disturbance operational states captured within internal model dynamics. For this purpose, two distinct DWDSs were exploited (each representing a different level of structural complexity). The examples illustrate that by utilising the derived model it can be possible to develop and validate monitoring, control and security algorithms able to handle a wider range of operational conditions than in the case of utilising a standard linear model with stationary parameters. Moreover, the developed algorithms can be designed in a manner that will prevent (the usually unpredicted) transitions to disturbance operational states due to the inappropriate control applied. Although the structure of this model is highly complex, which makes its direct application for monitoring, control and security model-based algorithms inappropriate, it can serve as a template to derive structures more suitable for these purposes. The numerical results were obtained utilising EPANET 2.0 (Rossman, 2000) multi-species extension (Shang and Rossman, 2011). 


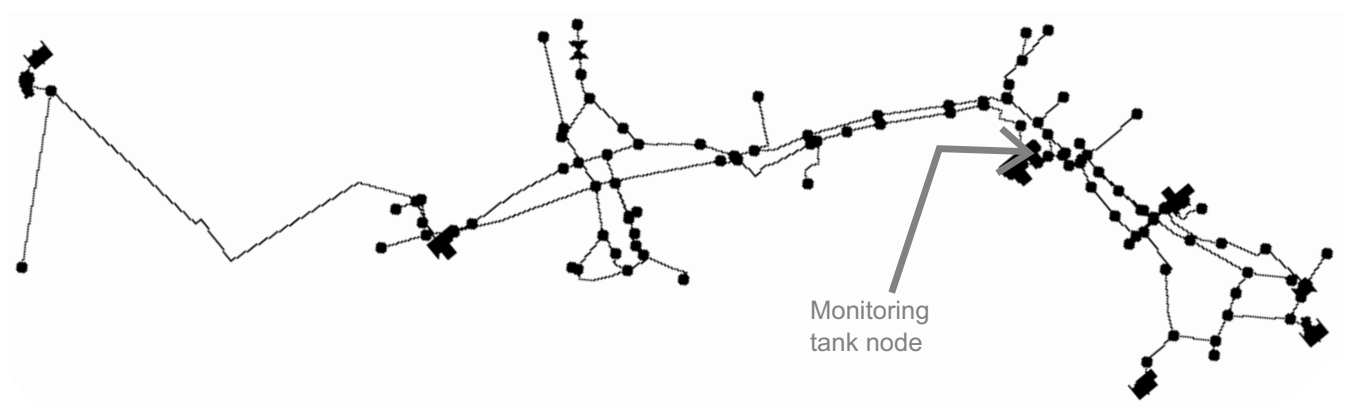

Fig. 5. Layout of the Gdynia DWDS.

\section{Conclusions}

This paper addressed the problem of modelling the advective transportation of reacting biochemical species within the DWDS. An integrated model structure was proposed to incorporate processes of disinfectant decay, biological regrowth, disinfection by-products formation and, above all, their complex interactions. This results in a high nonlinearity of the reactive part. Model parameters were obtained from experimental results published in the literature.

The goal of the work was to introduce a proper means of the development of on-line monitoring, control and security algorithms and their verification. Although the direct application of the full scale model proposed in this paper can be found computationally costly, it may serve well as a template for deriving reduced model structures more suitable for these purposes. Nevertheless, the full scale model itself can be utilised as a simulation tool for verification the monitoring, control and security algorithms purposes, as it is capable of simulating both normal and disturbance DWDS operational states and some of the possible transitions between them, as illustrated in Section 6

The on-going research is to add a sub-module to account for the security operational states (Brdys, 2010). This, however, to be done properly, will require a dedicated simulation environment able to accommodate features resulting from specific characterisation of the security operational state, e.g., to enable access to model internal states and introduce proper inputs and interactions with the existing modules.

\section{Acknowledgment}

This work was supported by the EU COST ACTION IC0806: Intelligent Monitoring, Control and Security of Critical Infrastructure Systems (IntelliCIS) and the Polish Ministry of Science and Higher Education through the grant no. 638/N COST/09/20/2010/0: Intelligent systems for monitoring, control and security of critical infrastructure plants: Methodology, structures, algorithms and applications to drinking water distribution networks (InSIK)
(EU Cost Action IC0806-IntelliCIS, 2008). The authors wish to express their thanks for the support.

\section{References}

Antonious, P. (1989). Determination of Biokinetic Coefficients for Nitrification in the Activated Sludge Process, Master's thesis, University of Florida, Gainesville, FL.

Arminski, K. and Zubowicz, T. (2011). Multispecies quality model for drinking water distribution system. InSIK technical report v.2.0., Technical report, Gdańsk University of Technology, Gdańsk.

Bitton, G. (1998). Formula Handbook for Environmental Engineers and Scientists, John Wiley and Sons, New York, NY.

Bousher, A., Brimblecombe, P. and Midgley, D. (1986). Rate of hypobromite formation in chlorinated seawater, Water Research 20(7): 865-870.

Brdys, M. (2010). Intelligent monitoring and control for critical infrastructure systems and application to integrated wastewater treatment systems, 12th IFAC Symposium on Large Scale Systems: Theory and Applications, Lille, France, Vol. 9, pp. 2-12, DOI: 10.3182/20100712-3-FR-2020.00003.

Brdys, M. and Ulanicki, B. (1994). Operational Control of Water Systems: Structures, Algorithms and Applications, Prentice Hall Int, Upper Saddle River, NJ.

Bull, R.J., Reckhowb, D.A., Li, X., Humpaged, A.R., Joll, C. and Hrudeyc, S.E. (2011). Potential carcinogenic hazards of non-regulated disinfection by-products: Haloquinones, halo-cyclopentene and cyclohexene derivatives, n-halamines, halonitriles, and heterocyclic amines, Toxicology 286(1): 1-19, DOI:10.1016/j.tox.2011.05.004.

Chowdhury, S., Champagne, P. and McLellan, P.J. (2009). Models for predicting disinfection byproduct (DBP) formation in drinking waters: A chronological review, Science of the Total Environment 407(14): 4189-4206, DOI:10.1016/j.scitotenv.2009.04.006.

Clark, R. M., and Sivaganesan, M. (2002). Predicting chlorine residuals in drinking water: Second order model, Journal of Water Resources Planning and Management 128(2): 152-151.

Davis, M. and Robert, J.D. (2003). Fundamentals of Chemical Reaction Engineering, McGraw-Hill, New York, NY. 
Deborae, M. and von Guten, U. (2008). Reactions of chlorine with inorganic and organic compounds during water treatment kintetics and mechanisms: A critical review, Water Research 42(1-2): 13-51, DOI:10.1016/j.watres.2007.07.025.

Digiano, F. and Zhang, W. (2008). Uncertainty analysis in a mechanistic model of bacterial regrowth in distribution system, Environmental Science \& Technology 38(22): 5925-5931, DOI:10.1021/es0497451.

Duirk, S., Gombert, B., Choi, J. and L., V.R. (2002). Monochloramine loss in the presence of humic acid, Journal of Environmental Monitoring 4(1): 85-89, DOI: $10.1039 / \mathrm{b} 106047 \mathrm{n}$.

EU Cost Action IC0806-IntelliCIS (2008). Memorandum of Understanding, 7th Framework Program, http://www.intellicis.eu.

EU Council Directive (1998). Council Directive 98/83/EC of 3 November 1998 on the Quality of Water Intended for Human Consumption, http://eur-lex.europa.eu.

Frateur, I., Deslouis, C., Kiene, L., Levi, Y. and Tribollet, B. (1999). Free chlorine consumption induced by cast iron corrosion in drinking water distribution systems, Water Research 33(8): 1781-1790.

Gazda, M. and Margerum, D.W. (1994). Reactions of monochloramine with br2, br-3, hobr, and obr-: Formation of bromochloramines, Inorganic Chemistry 25(19): 118-123.

Gray, J.E.T., Margerum, D.W. and Huffman, R.P. (1978). Chloramine equilibria and the kinetics of disproportionation in aqueous solution, in F.E. Brinckman and J.M. Bellama (Eds.), Organometals and Organometalloids: Occurrence and Fate in the Environment, ACS Books, Washington, DC, pp. 264-277.

Hammes, F., Vital, M., Egli, T., Rubulis, J. and Juhna, T. (2007). Modeling planktonic and biofilm growth of a monoculture (p. fluorescens) in drinking water, TECHNEAU Project Deliverable 5.5.9, http: //www.techneau.org/fileadmin/files/ Publications/Publications / Deliverables/ D5.5.9.pdf

Hand, V.C. and Margerum, D.W. (1983). Kinetics and mechanisms of the decomposition of dichloramine in aqueous solution, Inorganic Chemistry 22(10): 1449-1456, DOI: 10.1021/ic00152a007.

Helbling, D. and VanBriesen, J. (2009). Modeling residual chlorine response to a microbial contamination event in drinking water distribution systems, Journal of Environmental Engineering 135(10): 918-927, DOI:10.1061/(ASCE)EE.1943-7870.0000080.

Hong, Y., Liu, S. and Karanfil, T. (2008). Understanding DBP formation during chloramination, Florida Water Resource Journal 60(4): 51-53.

Hrudey, S.E. (2009). Chlorination disinfection by-products, public health risk tradeoffs and me, Water Research 43(8): 2057-2092, DOI:10.1016/j.watres.2009.02.011.
Jafvert, C.T. and Valentine, R.L. (1987). Dichloramine decomposition in the presence of excess ammonia, Water Research 21(8): 967-973.

Jegatheesan, V., Kastl, G., Fisher, I., Chandy, J. and Angles, M. (2003). Water quality modelling for drinking water distribution systems, International Congress on Modelling and Simulation, Townsville, Australia, pp. 332-337.

Jegatheesan, V., Kastl, G., Fisher, I., Chandy, J. and Angles, M. (2004). Modeling bacterial growth in drinking water: Effect of nutrients, Journal of AWWA (American Water Works Association) 96(5): 129-141.

Johnson, D.W. and Margerum, D.W. (1991). Non-metal redox kinetics: A reexamination of the mechanism of the reaction between hypochlorite and nitrite ions, Inorganic Chemistry 30(25): 4845-4851.

Kohpaei, A. and Sathasivan, A. (2011). Chlorine decay prediction in bulk water using the parallel second order model: An analytical solution development, Chemical Engineering Journal 171(1): 232-241, DOI:10.1016/j.cej.2011.03.034.

Leao, S.F. (1981). Kinetics of Combined Chlorine: Reaction of Substitution and Redox, Ph.D. thesis, University of California, Berkeley, CA.

LeChevallier, M., Welch, N. and Smith, D.B. (1996). Full-scale studies of factors related to coliform regrowth in drinking water, Applied and Environmental Microbiology 62(7): 2201-2211.

Liu:2005a Liu, S., Taylor, J., Randall, A.A. and Dietz, J. (2005a). Nitrification modeling in chloraminated distribution systems, American Water Works Association 97(10): 98-108.

Liu, S., Taylor, J.S. and Webb, D. (2005b). Water quality profiles during nitrification in a pilot distribution system study, Water Supply: Research and Technology-Aqua 54(3): 133-145.

Liu, W. and Qi, S. (2010). Modeling and verifying chlorine decay and chloroacetic acid formation in drinking water chlorination, Frontiers of Environmental Science \& Engineering in China 4(1): 65-72, DOI:10.1007/s11783-010-0010-y.

Lu C., Biswas P., Clark, R.M. (1995). Simultaneous transport of substrates, disinfectants and microorganisms in water pipes, Water Research 29(3): 881-894.

Łangowski, R. and Brdys, M.A. (2007). Monitoring of chlorine concentration in drinking water distribution systems using an interval estimator, International Journal of Applied Mathematics and Computer Science 17(2): 199-216. DOI: 10.2478/v10006-007-0019-y.

Margerum, D.W., Gray, E.T. and Huffman, R.P. (1978) Chlorination and the formation of N-chloro compounds in water treatment, in F.E. Brinckman and J.M. Bellama (Eds.), Organometals and Organometalloids: Occurrence and Fate in the Environment, ACS Books, Washington, DC, pp. 278-291. 
Margerum, D.W., Schurter, L.M., Hobson, J. and Moore, E.E. (1994). Water chlorination chemistry: Nonmetal redox kinetics of chloramine and nitrite ion, Environmental Science \& Technology 28(2): 331-337.

McKinney, R.E. (2004). Environmental Pollution Control Microbiology, Marcel Beckher, New York, NY.

Metcalf, E. and Tchobanoglous, G. (1978). Wastewater Engineering Treatment Disposal Reuse, McGraw-Hill, Upper Saddle River, NJ.

Morris, J.C. and Isaac, R.A. (1981). A critical review of kinetic and thermodynamic constants for the aqueous chlorine-ammonia system, in R.L. Jolley, W.A. Brungs, J.A. Cotruvo, R.B. Cumming, J.S. Mattice, and V.A. Jacobs (Eds.), Water Chlorination: Environmental Impact and Health Effects, Ann Arbor Science, Ann Arbor, MI, pp. 49-62.

Muellner, M.G., Wagner, E.D., McCalla, K., Richardson, S.D., Woo, Y.T. and Plewa, M.J. (2007). Haloacetonitriles vs. regulated haloacetic acids: Are nitrogen-containing DBPs more toxic?, Environmental Science and Technology 41(2): 645-651.

Myszor, D. and Cyran, K. (2013). Mathematical modeling of molecule evolution in protocells, International Journal of Applied Mathematics of Computer Science 23(1): 213-229, DOI: 10.2478/amcs-2013-0017.

Nokes, C., Fenton, E. and Randal, C. (1999). Modelling the formation of brominated trihalomatanes in chlorinated drinking waters, Water Research 33(17): 3557-3568.

Nowicki, A., Grochowski, M. and Duzinkiewicz, K. (2012). Data-driven models for fault detection using kernel PCA: A water distribution system case study, International Journal of Applied Mathematics of Computer Science 22(4): 939-949, DOI: 10.2478/v10006-012-0070-1.

Poduska, R.A. and Andrews, F.J. (1974). Dynamics of nitrification in the activated sludge process, 29th Industrial Waste Conference, Lafayette, IN, USA, pp. 2599-2619.

Pope, P.G. (2006). Haloacetic Acid Formation During Chloramination: Role of Environmental Conditions, Kinetics, and Haloamine Chemistry, Ph.D. thesis, University of Texas at Austin, TX.

Rossman, L.A. (2000). Epanet 2 users manual, Risk Reduction Engineering Laboratory, US EPA, Cincinnati, OH.

Rossman, L.A., Clark, R.M. and Grayman, W.M. (1994). Modeling chlorine residuals in drinking-water distribution-systems, Journal of Environmental Engineering 120(4): 803-820.

Sadiq, R. and Rodriguez, R.J. (2004). Disinfection by-products (DBPs) in drinking water and predictive models for their occurrence: A review, Science of the Total Environment 321(1-3): 21-46.

Shang, F. and Rossman, L. (2011). Epanet multi-specie extention user's manual, EPA/600/S-07/021, National Risk Management Research Laboratory, National Homeland Security Research Center Office of Research and Development, US Environmental Protection Agency, Cincinnati, $\mathrm{OH}$.
Shang, F., Uber, J. and Rossman, L. (2008). Modeling reaction and transport of multiple species in water distribution systems, Environmental Science \& Technology 42(3): 808-814, DOI: $10.1021 / \mathrm{es} 072011 \mathrm{z}$.

Snoeyink, V.L. and Jenkins, D. (1980). Water Chemistry, John Wiley and Sons, New York, NY.

Trofe, T.W., Inman, J.G.W. and Johnson, J.D. (1980). Kinetics of monochloramine decomposition in the presence of bromide, Environmental Science \& Technology 14(5): 544-549, DOI: 10.1021/es60165a008.

van der Kooij, D., Vrouwenvelder, H. and Veenendaal, $H$. (1995). Kintetic aspects of biofilm formation on surfaces exposed to drinking water, Water Science and Technology 32(8): 61-65, DOI:10.1016/0273-1223(96)00008-X.

Vikesland, P.J., Ozekin, K. and Valentine, R. (2001). Monochloramine decay in model and distribution system waters, Water Research 35(7): 1766-1776.

Williamson, K. and McCarty, P. (1976). Verification studies of the biofilm model for bacterial substrate utilization, Journal of Water Pollution Control Federation 48(2): 1281-289.

World Health Organisation (2005). Guidelines for drinking water quality. Dichloroacetic acid in drinking-water, $R e$ port No. WHO/SDE/WSH/05.08/121.

Zhang, W., Miller, C. and DiGiano, F. (2004). Bacterial regrowth model for water distribution systems incorporating alternating split-operator solution technique, Journal of Environmental Engineering 130(3): 932-941, DOI: 10.1060/(ASCE)0733-39372(2004)130:9(932).

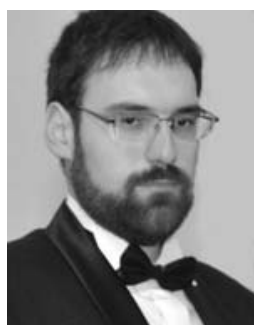

Krzysztof Arminski received his M.Sc. degree in control engineering in 2009 from the Electrical and Control Engineering Department at the Gdańsk University of Technology. Soon after he became a Ph.D. student in this department. Currently he is member of the project InSIK as a young researcher.

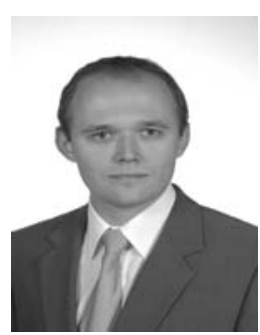

Tomasz Zubowicz received his M.Sc. degree in control engineering from the Faculty of Electrical and Control Engineering at the Gdańsk University of Technology in 2008. Then he began doctoral studies at the Department of Control Systems Engineering of the same university. In 2012 he became a permanent staff member at this department. His current research interests concern fuzzy control, model predictive control, biologically inspired control structures, monitoring, control and security of critical infrastructure systems. 


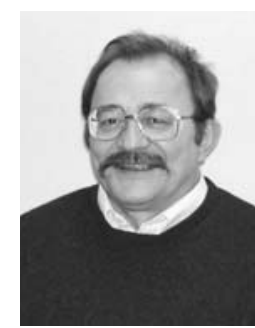

Mietek A. Brdys received the M.Sc. degree in electronic engineering and the Ph.D. and D.Sc. degrees in control systems from the Institute of Automatic Control at the Warsaw University of Technology in 1970, 1974 and 1980, respectively. From 1974 to 1983, he held the posts of an assistant professor and an associate professor at the Warsaw University of Technology. In 1992 he became a full professor of control systems in Poland. Between 1978 and 1995, he held various visiting faculty positions at the University of Minnesota, City University, De Montfort University and the University Polytechnic of Catalunya. Since 1989, he has held the post of a senior lecturer in the Department of Electronic, Electrical and Computer Engineering at the University of Birmingham, where he is the head of the Control and Decision Support Research Laboratory. Since 2001 he has held the post of a full professor of control systems in the Department of Automatic Control at Gdańsk University of Technology. In 2008 he founded there the Department of Control Systems Engineering and became its head. He has served as a consultant for the Honeywell Systems and Research Centre in Minneapolis, GEC Marconi and water authorities in the UK, France, Spain, Germany and Poland. His research is supported by the UK and Polish research councils, industry and the European Commission. He is an author and co-author of about 220 refereed papers and six books. His current research includes intelligent decision support and control of large scale complex systems, robust monitoring and control, softly switched robustly feasible model predictive control and integrated monitoring, control and security of critical infrastructure systems. The applications include environmental systems, technological processes, power smart grids and defence systems. He is a chartered engineer, a member of the IEE, a senior member of the IEEE, a fellow of the IMA and the chair of the IFAC Technical Committee on Large Scale Complex Systems. He was the IPC chair of the 11th IFAC Symposium on Large Scale Complex Systems, Gdańsk, 2007, and will serve as the IPC chair for the 13th Symposium on LSCS, Shanghai, 2013.

Received: 27 August 2012

Revised: 27 May 2013 